\title{
Impact of Age, Activity and Diet on the Conditioning Performance in the Ant Myrmica ruginodis Used as a Biological Model (Hymenoptera, Formicidae)
}

\author{
Marie-Claire Cammaerts ${ }^{1} \&$ Geoffrey Gosset ${ }^{1}$ \\ ${ }^{1}$ Faculté des Sciences, Université Libre de Bruxelles, Bruxelles, Belgium \\ Correspondence: Marie-Claire Cammaerts, Faculté des Sciences, DBO, CP 160/12, Université Libre de \\ Bruxelles, 50, Av. F. D. Roosevelt, 1050 Bruxelles, Belgium. E-mail: mtricot@ulb.ac.be
}

Received: December 9, 2013 Accepted: January 3, 2014 Online Published: January 9, 2014

doi:10.5539/ijb.v6n2p10

URL: http://dx.doi.org/10.5539/ijb.v6n2p10

\begin{abstract}
Myrmica ruginodis Nylander 1846 workers either of different ages, or having their food at different distances from the nest, or receiving different diet were submitted to identical operant conditioning. Very young ants (callow ants) could not be visually conditioned. Ants one to two years old rapidly acquired visual conditioning, presenting a score of $90 \%$ after $70 \mathrm{hrs}$ and going on presenting a score of $80 \%, 369 \mathrm{hrs}$ after training ended. Old ants acquired visual conditioning with difficulty, reaching only a score of $65 \%$ and retaining nothing of their conditioning. Ants having their food at $5 \mathrm{~cm}$ from their nest acquired $85 \%$ of conditioning in 2 days and memorized $75 \%$ of it; those having their food at $10 \mathrm{~cm}$ from their nest acquired $80 \%$ of conditioning in 3 days and retained $65 \%$ of it; the ants having their food at $15 \mathrm{~cm}$ from their nest (e.g. in the vicinity of their cemeteries) acquired $75 \%$ of conditioning in $31 / 2$ days and remembered $60 \%$ of it. Conditioning is thus more efficiently acquired when individuals' activity is limited. Ants having received no sugar could not acquire conditioning; those having eaten sugar could be easily conditioned. The quantity of sugar provided slightly impacted the ants' conditioning: the ants consumed only what they needed. The influence of the three factors examined - age, activity, diet - allows us to understand some trends of the ants' life and is valuable in the context of other animal species.
\end{abstract}

Keywords: callow ants, carbohydrate, memory, learning, training

\section{Introduction}

Habituation and imprinting, then conditioning and learning are animals' essential abilities which, with several other abilities such as kin recognition and navigating, often allow their survival (Pearce, 1997). Classical and operant conditioning has largely been studied in many vertebrate and invertebrate species. Famous authors can be cited: Vertebrates: Pavlov (1927), Watson (1925, 1932), Skinner (1938, 1966); Invertebrates: Matsumoto, Menzel, Sandoz and Giurfa (2012), Laloi et al. (1999).

The conditioning method impacts individuals' performances. For instance, harnessed ants are generally very quickly conditioned (Guerrieri \& d'Ettorre, 2010) while free moving ones acquire similar conditioning more slowly (Schwarz \& Cheng, 2010). The same occurs for bees (Giurfa, 2003). Other factors may also influence the animals' conditioning score and memory, i.e. age, activity, diet.

It is known that age and experience influence ants' kin recognition (Gronenberg, Heeren, \& Hölldobler, 1996) and that ants' spatio-temporal learning depends on the individuals' age (Cammaerts, 2013a). In fact, age-polyethism obviously exists in social insects and has largely been examined (Hölldobler \& Wilson, 1990). Personal observations lead to the supposition that individuals' activity also influences their ability in acquiring conditioning: for instance, during nest relocation, conditioning could nearly not be obtained. It has also been shown that diet affects bees' health (Alaux, Ducloz, Crauser, \& Le Conte, 2010) and that caffeine boots these insects' memory (Chittka \& Peng, 2013).

Ants can easily be maintained in a laboratory throughout the entire year. They are very sensitive and detain plenty of cognitive abilities (Passera \& Aron, 2005; Cheng \& Wehner, 2002; Dornhaus \& Franks, 2008; Chittka \& Muller, 2009). They can also easily be conditioned (Dupuy, Sandoz, Giurfa, \& Josens, 2006; Cammaerts, 2004 a, 2004b). Such conditioning even helped in studying these insects' sensorial capabilities (Cammaerts, 2007). They are thus 
excellent and convivial biological models for experimenting on many subjects (chemical communication, navigation systems, social organization), and, among others, on conditioning and its different parameters.

It was decided to use ants as a model, and more specifically the ant Myrmica ruginodis Nylander 1846, to examine the impact of three factors (age, activity and diet) on animals' conditioning. In nature, Myrmica spp workers are expected to live for three years (Cammaerts, 1977). Myrmica ruginodis inhabits borders of forests, nests under branches where the sky is partly visible together with the canopy. It has rather large eyes (169 ommatidia; Rachidi, Cammaerts, \& Debeir, 2008) and uses exclusively its vision in navigating (Cammaerts, Rachidi, Beke, \& Essaadi, 2012a). It can be visually but not olfactory conditioned under lighting condition. When collectively conditioned, these ants acquired a conditioning score of $80 \%$ and kept $75 \%$ of it after training ceased (Cammaerts \& Nemeghaire, 2012). Our aim was to examine the impact of the three above cited factors (age, activity, diet) on $M$. ruginodis workers' visual conditioning. It was easy to segregate the workers of a colony into groups of differently aged individuals, to increase or decrease the workers' foraging activity and to modify their usual diet. So, we could performed the three planned studies what allowed us deducing information about ants' patterns of life and extending some findings to other animal species. The present paper relates these works.
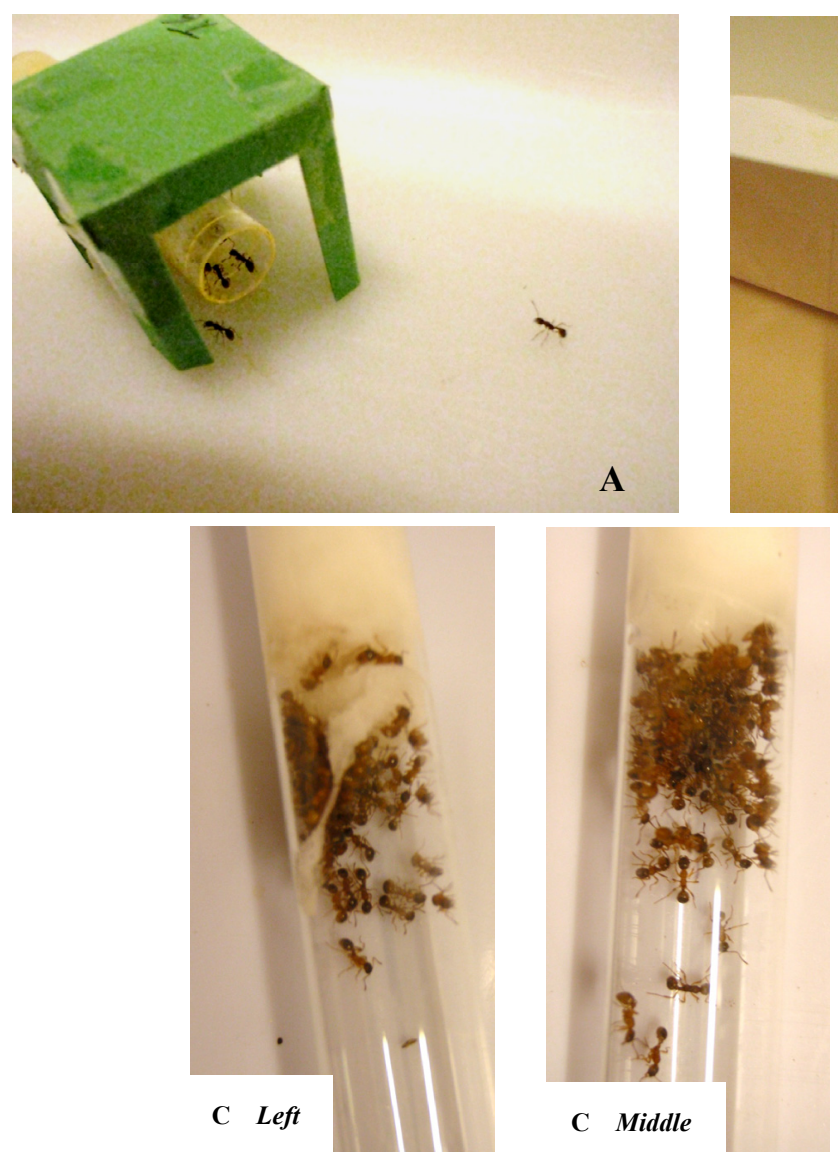
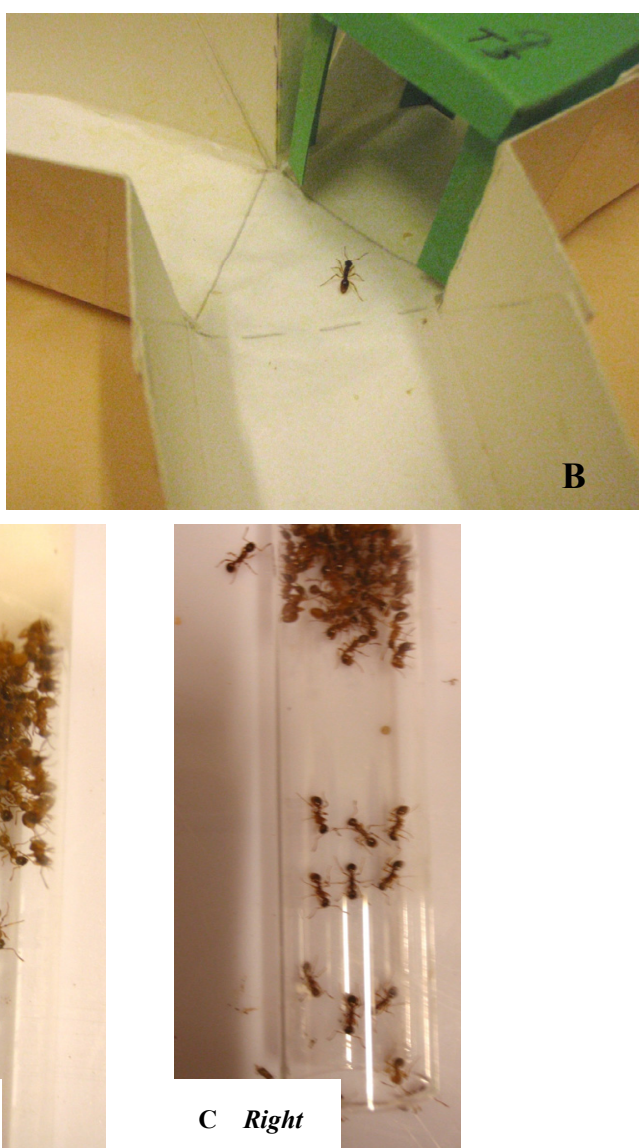
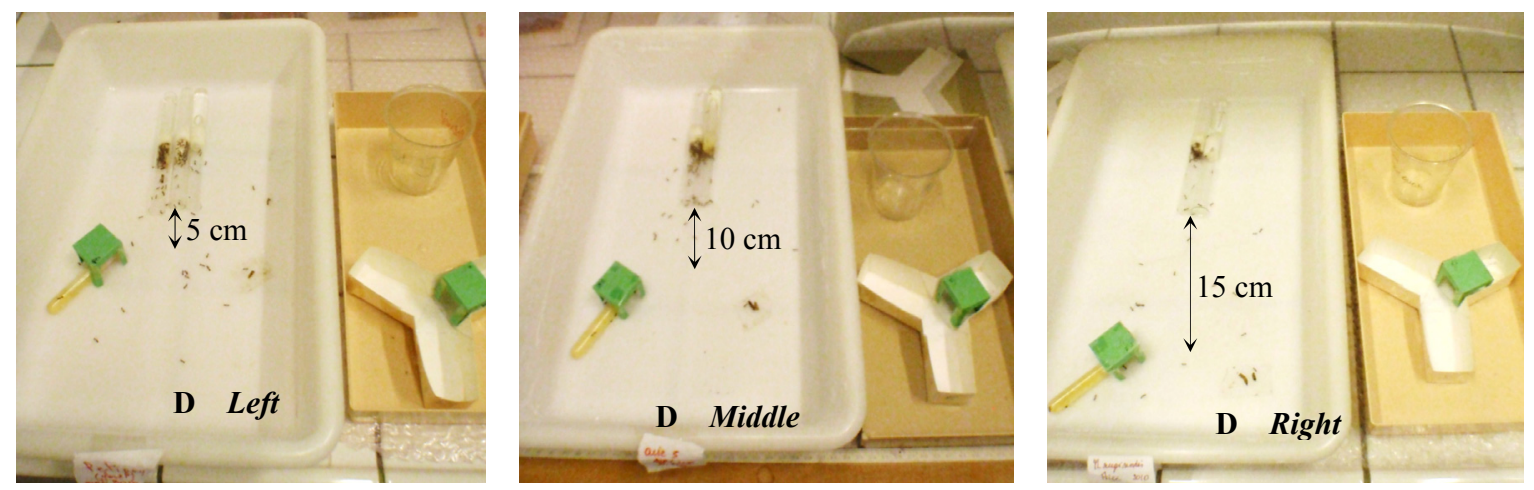

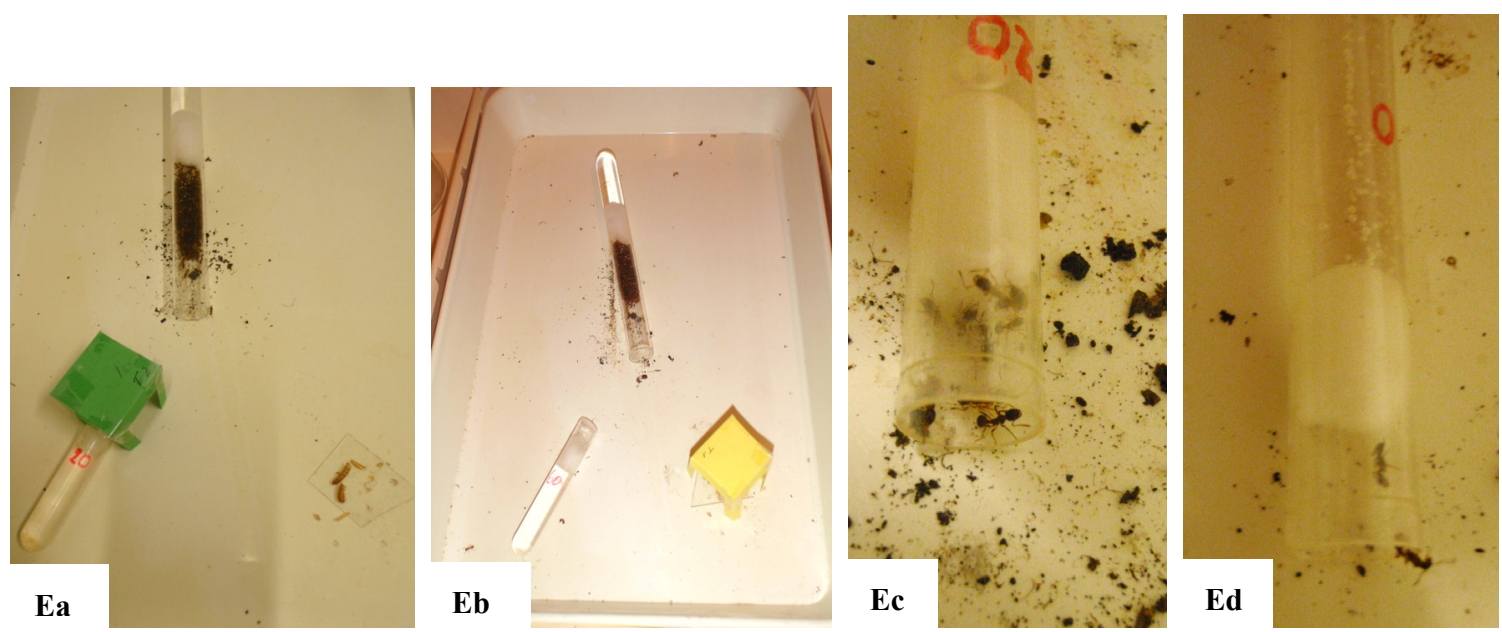

Figure 1. Some views of the experiments. A: ants' training; B: ants' testing; C: very young ants (Left photo), middle-aged ones (Middle photo) and old ants (Right photo) used for examining the impact of age on the conditioning; D: the ants' food was set at $5 \mathrm{~cm}$ (Left photo), or at $10 \mathrm{~cm}$ (Middle photo), or at $15 \mathrm{~cm}$ (Right photo) from the nest, to study the impact of foraging activity on conditioning; E: impact of diet on the conditioning: a: ants are trained to a green cube set on the watered food, b: ants are trained to a yellow cube set on the meat food, c: many ants collected a $20 \%$ sugared water, $d$ : few ants collected a $60 \%$ sugared water

\section{Material and Methods}

\subsection{Collection and Maintenance of Ants}

The present work was conducted on eight colonies of M. ruginodis. Two large colonies and a small one were collected, in 2010, in the Aise valley (Ardenne, Belgium); one colony was collected, in 2010, at Petigny (Ardenne, Belgium). A very large colony was collected, in 2013, in the Viroin valley, at Treigne (Ardenne, Belgium) and three colonies could be again collected, in 2013, in the Aise valley (Ardenne, Belgium). In each case, they inhabited the borders of forests, under branches, where the sky was partly visible, the ants often nesting under stones. The large colony collected in the Viroin valley was used to study the impact of the individuals' age on their conditioning; the two large colonies collected in 2010 in the Aise valley and that collected at Petigny were used to study the impact of individuals' activity on the conditioning performance; the colonies collected in 2013 in the Aise valley served to examine the effect of diet on the animals' conditioning. The small colony collected, in 2010, in the Aise valley allowed making control experiments.

Each collected colony contained one to four queens, brood (larvae, nymphs) and about 500 workers. The colonies were maintained in the laboratory in artificial nests made of one to three glass tubes half-filled with water, a cotton-plug separating the ants from the water. During the ants' maintenance, the glass tubes were deposited in trays $(34 \mathrm{~cm} \times 23 \mathrm{~cm} \times 3 \mathrm{~cm}$ ), the sides of which were covered with talc (Figure 1Eb). The trays served as foraging areas, food being delivered in them. The ants were fed with sugar-water provided ad libitum in a small glass tube plugged with cotton, as well as with a droplet of tap water set on the foraging area and with cut Tenebrio molitor larvae served three times a week on a glass-slide. Some feeding conditions varied in the course of given experiments. Temperature was maintained at $20 \pm 2{ }^{\circ} \mathrm{C}$, humidity at about $80 \%$, this remaining constant over the course of the experimentation. The lighting had a constant intensity of 330 lux when caring for the ants (e.g. providing food, renewing nesting tubes) and testing them; during other time periods, the lighting was dimmed to 110 lux. The electromagnetic field had an intensity of $3-5 \mu \mathrm{W} / \mathrm{m}^{2}$.

\subsection{Experimental Apparatus}

\subsubsection{Ants' Conditioning}

Ants of each experimental colony were collectively visually trained using an experimental apparatus consisting of a hollow green cube constructed of strong paper (Canson $\left.{ }^{\circledR}\right)$. The colors have been analyzed to determine their wavelength reflection (Cammaerts, 2007; M.-C. Cammaerts \& D. Cammaerts, 2009). The cubes were constructed according to the instructions given in Cammaerts and Nemeghaire (2012). The ceiling of each cube was filled unlike the four vertical faces, this allowing the ants entering the cubes. The hollow green cube of each experimental colony was set over the opening of the cotton plugged tube filled with sugared water (Figure 1A). 
Each cube was relocated once or twice each day, but never according to a regular itinerary (such as every $12 \mathrm{~h}$ or $24 \mathrm{~h}$ ), and the reward was then renewed if necessary. This was done to avoid the establishment of a trail (M.-C. Cammaerts \& R. Cammaerts, 1980), and to prevent the acquisition of spatial and/or temporal learning by the ants (Cammaerts, 2004a). The green cube was considered to be the 'correct' choice when the ants were tested as explained below. In one experiment, the ants were also trained using a hollow yellow cube set above the cut $T$. molitor larvae (as explained in the section ' 3 . Results 3.3', Figure 1Eb).

\subsubsection{Ants' Testing}

Ants were individually tested in a Y-shaped apparatus constructed of strong white paper according to the instructions given in Cammaerts, Rachidi and Cammaerts (2011), and set in a small tray $(30 \mathrm{~cm} \times 15 \mathrm{~cm} \times 4 \mathrm{~cm})$, apart from the experimental colony's tray (Figure 1B). Each colony had its own testing design. The apparatus had its own bottom and the sides were covered with talc to prevent the ants from escaping. In the Y-apparatus, the ants deposited no trail since they were not rewarded. However, it is possible that they utilized other chemical secretions as traces. As a precaution, the floor of each Y-apparatus was changed between tests. The Y-apparatus was provided with a green cube - or a yellow one, in one experiment - in one or the other branch (Figure 1B). The branch was randomly chosen, while also ensuring that half of the tests was conducted with the cube in the left branch and the other half with the cube in the right branch of the Y maze. Control experiments were performed using also such Y-apparatus, on never conditioned ants belonging to the small colony recolted, in 2010, in the Aise valley (see 2.1, end of the first alinea).

To conduct a test on an experimental colony, 20 workers of that colony - randomly chosen from the workers of that colony - were transferred one by one to the area at the entrance of the Y-apparatus. Each transferred ant was observed until it turned either to the left or to the right in the Y-maze, and its choice was recorded. Only the first choice of the ant was recorded and this only when the ant was entirely under the cube, i.e. beyond a pencil drawn thin line indicating the entrance of a branch (Figure 1B). Afterwards, the ant was removed and transferred to a polyacetate cup, in which the rim was covered with talc, until 20 ants were so tested, this avoiding testing the same ant twice. All the tested ants were then placed back on their foraging area. To conduct controls, 20 ants of a non-conditioned colony were similarly tested in identicalY-apparatus.

\subsection{Assessment of the Ants' Response}

The ants' responses were quantified during the control and test experiments. In each experiment, the numbers of ants which turned left or right during the control experiments, or which approached the "correct" green (or the yellow) cube, or went to the "wrong" empty branch of the Y were recorded. The mean number of ants which correctly responded per colony was assessed and the percentage of correct responses for the tested ant population was established (Tables 1,2 and 3).

For each experiment, the number of correct responses was statistically analyzed using the non-parametric $\chi^{2}$ test applied to the experimentally obtained values and the theoretical expectation of identical values for the two branches of the Y maze. Since we did not compare the results of each successive assessment to the same control, the Bonferroni correction must not be applied. Responses were considered as being not significant when $\mathrm{P}>0.05$ (Siegel \& Castellan, 1989).

\subsection{Experimental Protocol}

In general, tests were performed in the course of time, at least once per day. The start was given by the colored cube deposit on the ants' tray. As soon as the ants' conditioning score no longer changed (neither increased nor decreased), the training apparatus was removed from the foraging area of the colony and tests were once more started, until the ants' memory (or retention) score showed no further change (neither increase or decrease).

\subsection{Experimental Planning}

\subsubsection{Impact of Individuals' Age}

The large colony collected at Treigne was divided in four smaller ones: one contained the older ants foraging on the tray; a second one was made up of ants located in the foraging area as well as near the nest entrances (outside and inside); a third colony consisted of the very young ants, lighter in color than the first and the second groups, located inside the nest; the fourth colony was made up of the queen and the unselected ants e.g. a few old, middle-aged and young ones. Brood elements (eggs, larvae, nymphs) were equally distributed between the first three newly constituted smaller colonies. Each new colony was maintained in a glass tube half filled with water (Figure 1C), in a tray $(34 \mathrm{~cm} \times 23 \mathrm{~cm} \times 3 \mathrm{~cm})$ as usual and their meat and sugar food was located on the left and the right respectively of the nest entrance at $7 \mathrm{~cm}$ of distance. The fourth colony was not tested. At a precise time, a hollow green cube was set above the opening of the small glass tube containing the sugar water of each of the three 
experimental colonies, and the training of these colonies began. Tests were then conducted, as explained above, on the course of the ants' conditioning acquisition, and then of their conditioning loss (Table 1).

\subsubsection{Impact of Individuals' Foraging Activity}

Three colonies of $M$. ruginodis were transferred into somewhat larger trays $(42 \mathrm{~cm} \times 27 \mathrm{~cm} \times 7 \mathrm{~cm})$ so that their food could be located as follows. For each colony, the sugar food was located to the right of the nest entrance while the meat food was on the left. For the first colony, the distance between the food sites and the nest entrance was 5 $\mathrm{cm}$; for the second colony, this distance was $10 \mathrm{~cm}$; for the third colony, the distance between food and nest entrance was $15 \mathrm{~cm}$, the food being so nearly as distant as the colony cemeteries which are always established, by the ants, in one, some or all corners of the colony tray (Figure 1D). As explained above, training consisted in setting a hollow green cube above the opening of the small glass tube containing sugared water (sugar food). Ants progressively associated the green cube and the presence of sugar food, thus undergoing operant conditioning. As soon as the training apparatus were set in place, time was continuously checked and ants were tested, as detailed above, in the course of their conditioning acquisition, and then their conditioning loss (or potential loss) (Table 2).

\subsubsection{Impact of Individuals' Diet}

Three colonies were used to examine the impact of individual diet on conditioning. For each of these colonies, the small tube containing the sugar water was removed and replaced by an identical small tube but filled with a given, experimental diet (Figure 1E).

For one colony, this diet consisted in tap water. The diet of the second colony was diluted sugared water ( $20 \%$ saccharose). For the third colony, the diet was a concentrated aqueous solution of sugar ( $60 \%$ saccharose). The experiments were performed with firstly a hollow green cube above the tube containing the aqueous solution (Figure 1Ea), then, secondly, with a hollow yellow cube above the T. molitor larvae (Figure 1Eb). Also, as a precaution, the colony having received tap water during the first experiment received $20 \%$ aqueous solution of saccharose in the course of the second experiment; that having received the diluted solution during the first experiment was given $60 \%$ solution of saccharose in the course of the second experiment; the colony having first received the more concentrated sugar solution then received only tap water. As soon as the hollow cubes were set in place, time was recorded and the tests performed, as previously until the ants reached their maximum conditioning score (Table 3).

\section{Results}

\subsection{Impact of Individuals' Age on Their Conditioning Performance}

Table 1. Number of correct choices versus wrong ones - and proportion of correct responses - given by Myrmica ruginodis workers of different ages

\begin{tabular}{|c|c|c|c|c|c|c|}
\hline \multirow{3}{*}{$\begin{array}{c}\text { Experiments } \\
\text { Times } \\
\text { Control }\end{array}$} & \multicolumn{6}{|c|}{ Approximate age of tested ants } \\
\hline & \multicolumn{2}{|c|}{3 - 4 months } & \multicolumn{2}{|c|}{$1-2$ years } & \multicolumn{2}{|c|}{$2-3$ years } \\
\hline & & & 9 vs 10 & $45 \%$ & & \\
\hline Tests $22 \mathrm{hrs}$ & $10 v s 10$ & $50 \%$ & 14 vs 7 & $70 \%$ & 12 vs 8 & $60 \%$ \\
\hline $30 \mathrm{hrs}$ & 10 vs 10 & $50 \%$ & 15 vs 5 & $75 \%$ & 12 vs 8 & $60 \%$ \\
\hline $43 \mathrm{hrs}$ & $10 v s 10$ & $50 \%$ & $16 v s 4$ & $80 \%$ & 13 vs 7 & $65 \%$ \\
\hline $58 \mathrm{hrs}$ & $\rightarrow 10$ vs 10 & $50 \%$ & 17 vs 3 & $85 \%$ & $12 v s 8$ & $60 \%$ \\
\hline $70 \mathrm{hrs}$ & & & $18 v s 2$ & $90 \%$ & $\rightarrow 11 v_{S} 9$ & $55 \%$ \\
\hline $84 \mathrm{hrs}$ & & & $\rightarrow 17 v_{s} 3$ & $85 \%$ & 10 vs 10 & $50 \%$ \\
\hline $94 \mathrm{hrs}$ & & & $16 v s 4$ & $80 \%$ & 10 vs 10 & $50 \%$ \\
\hline $118 \mathrm{hrs}$ & & & 17 vs 3 & $85 \%$ & 10 vs 10 & $50 \%$ \\
\hline $141 \mathrm{hrs}$ & & & 17 vs 3 & $85 \%$ & & \\
\hline $170 \mathrm{hrs}$ & & & 16 vs 3 & $80 \%$ & & \\
\hline $192 \mathrm{hrs}$ & & & 18 vs 2 & $90 \%$ & & \\
\hline $238 \mathrm{hrs}$ & & & 17 vs 3 & $85 \%$ & & \\
\hline
\end{tabular}

The cue at which ants were conditioned was a green hollow cube, set above the ants' sugar water, at 0 hrs for 
each kind of ants and removed $(\rightarrow$ ) at $72 \mathrm{hrs,} 96 \mathrm{hrs,} 104 \mathrm{hrs}$ respectively for very young ants, middle aged ants, and rather old ones. A black circle $(\bigcirc$ ) indicates the acquisition of full conditioning.

During the control experiment, statistically as many ants moved into each branch of the $\mathrm{Y}$ apparatus, a hollow green cube being present ( 9 out of 20 ants) or not (11 out of 20 ants) (Table 1, line 1).

The callow ants never acquired visual conditioning. Even after $58 \mathrm{hrs}$ of training, they continued to hesitate when confronted with a hollow green cube on one hand and an empty branch on the other (Table 1, second column). Middle aged ants very quickly acquired visual conditioning and reached the spectacular score of $90 \%$ after $70 \mathrm{hrs}$. After their training ended, they went on responding to the green cube, presenting a score of $85 \%, 85 \%, 80 \%, 90 \%$, $85 \%, 85 \%, 80 \%, 34 \mathrm{hrs}, 57 \mathrm{hrs}, 86 \mathrm{hrs}, 108 \mathrm{hrs}, 154 \mathrm{hrs}, 202 \mathrm{hrs}, 369 \mathrm{hrs}$ later respectively. Middle aged ants appeared so to have a strong visual memory. Very old ants had difficulty in acquiring visual conditioning. When tested, they often stopped and moved their head upon their arrival at the decision point of the Y-apparatus. After 43 hrs, they acquired a score of only $65 \%$ which thereafter decreased to $60 \%$ and $55 \%$. They retained nothing of their weak conditioning.

\subsection{Impact of Individuals' Foraging Activity on Their Conditioning Performance}

A control experiment, conducted using the small colony collected in 2010 in the Aise valley, on non-conditioned ants, showed that such ants chose the empty branch of the Y maze as often as that with a hollow green cube (Table 2, line 1).

Table 2. Number of correct choices versus wrong ones - and proportion of correct responses - given by Myrmica ruginodis foragers which food (so cue and reward) was set at different distances from the nest

\begin{tabular}{|c|c|c|c|c|c|c|}
\hline \multirow{3}{*}{$\begin{array}{c}\text { Experiments } \\
\text { Times } \\
\text { Control }\end{array}$} & \multicolumn{6}{|c|}{ Distances between nest and food (so cue and reward) } \\
\hline & \multicolumn{2}{|c|}{$5 \mathrm{~cm}$} & \multicolumn{2}{|c|}{$10 \mathrm{~cm}$} & \multicolumn{2}{|c|}{$15 \mathrm{~cm}$} \\
\hline & & & $10 v s 10$ & $50 \%$ & & \\
\hline Tests $24 \mathrm{hrs}$ & $15 v s 5$ & $75 \%$ & 12 vs 8 & $60 \%$ & $10 v s 10$ & $50 \%$ \\
\hline $32 \mathrm{hrs}$ & $16 v s 4$ & $80 \%$ & 14 vs 7 & $70 \%$ & 11 vs 9 & $55 \%$ \\
\hline $48 \mathrm{hrs}$ & $17 v s 3$ & $85 \%$ & 15 vs 5 & $75 \%$ & 13 vs 7 & $65 \%$ \\
\hline $72 \mathrm{hrs}$ & $\rightarrow 15$ vs 5 & $75 \%$ & $16 v s 4$ & $80 \%$ & 15 vs 5 & $75 \%$ \\
\hline $96 \mathrm{hrs}$ & 13 vs 7 & $65 \%$ & $\rightarrow 15$ vs 5 & $75 \%$ & $\rightarrow 14$ vs 6 & $70 \%$ \\
\hline $119 \mathrm{hrs}$ & $14 v s 6$ & $70 \%$ & 13 vs 7 & $65 \%$ & 11 vs 9 & $55 \%$ \\
\hline $144 \mathrm{hrs}$ & $15 v s 5$ & $75 \%$ & 13 vs 7 & $65 \%$ & 12 vs 8 & $60 \%$ \\
\hline $168 \mathrm{hrs}$ & & & 13 vs 7 & $65 \%$ & 12 vs 8 & $60 \%$ \\
\hline $192 \mathrm{hrs}$ & & & & & $12 v s 8$ & $60 \%$ \\
\hline
\end{tabular}

The cue at which ants were conditioned was set in place at $0 \mathrm{hrs}$ for each colony and removed $(\rightarrow)$ at $72 \mathrm{hrs}, 96$ hrs, $104 \mathrm{hrs}$ respectively for colonies which food was presented at $5 \mathrm{~cm}, 10 \mathrm{~cm}, 15 \mathrm{~cm}$ from the nest, so after full conditioning was achieved $(\bigcirc)$.

All the trained ants could acquire operant conditioning but with different performances according to the foraging activity they need for collecting their food (Figure 1D).

When meat and sugar food was located very near the nest entrance (Figure 1D, Left photo), ants presented a very short latency period (about $12 \mathrm{hrs)}$ before acquiring a conditioning score of $85 \%$ in 48 hrs. Training then being stopped, the ants slowly lost their conditioning (in about three days) and kept $75 \%$ of it (Table 2, second column).

Ants receiving their meat and sugar food at middle distance between their nest entrance and the borders of their foraging area (Figure 1D, middle photo) presented a latency period of about $35 \mathrm{hrs}$ and then acquired an operant conditioning of $80 \%$ in about three days $(\approx 72 \mathrm{hrs})$. The training ending at that time, the ants kept their conditioning for a short time (about 10 - $15 \mathrm{hrs}$ ), then lost it in about $20 \mathrm{hrs}$ and kept $65 \%$ of it (Table 2, third column).

The ants having their meat and sugar food far from their nest entrance (e.g. at nearly the same distance as their cemeteries) presented a relatively long latency period (about 3 days), then acquired conditioning with a score of 
$75 \%$ in about a total of $84 \mathrm{hrs}$. After the end of the training, these ants soon lost their conditioning (either with no latency period, or with a short barely perceptible one) and kept only $60 \%$ of it (Table 2 , fourth column).

\subsection{Impact of Diet on Individuals' Conditioning Performance}

Again, control experiments showed that non-conditioned ants moved at random through a $Y$ maze provided with a hollow green or yellow cube in one of its branches (Table 3, control with each kind of cube).

The results regarding the consumption or the non-consumption of sugar by the ants were unexpected. When the hollow green cubes were set above the aqueous solutions provided, the ants receiving only tap water never acquired conditioning. At the beginning, they often walked quickly all around the provided water, and after one day, they scarcely came to drink the offered water. On the contrary, the ants receiving a $20 \%$ aqueous solution of saccharose very quickly acquired visual conditioning, moved quietly on the area and were often numerous in drinking the sugar water offered. The ants having a $60 \%$ aqueous solution of saccharose at their disposal very quickly acquired visual conditioning but reached a lower score than the ants consuming a more diluted solution (Table 3, upper part). They were calm but not very numerous in drinking the solution offered. It was also observed that ants receiving only tap water ate an entire T. molitor larva in one day, while during that time, those having diluted sugar water ate only half a larva and the ants having a concentrated solution of sugar did not eat the larva which was found intact after one day. The non-acquisition of conditioning by the ants receiving no sugar may be due to the fact that the cube was set above tap water which is not a true reward for the ants. So, the experiment was reproduced using a yellow cube, this cube being set above the meat food. When hollow yellow cubes were set above the meat food, the results were similar to the previous ones: the ants receiving no sugar, though having in this case a true reward under the cues to memorize, never acquired visual conditioning, while the other ants acquired such conditioning perfectly. The latter ants' score was a little lower that the score obtained when rewarding the ants with sugared water, this being usual behavior for ants (M.-C. Cammaert, Rachidi, \& D. Cammaerts, 2011). As with the green cube above the sugar food, the ants receiving $20 \%$ sugared water reached a better (but not statistically better) score than those receiving 60\% sugared water (Table 3, lower part). It was continuously observed that more ants visited the $20 \%$ solution of sugar than the $60 \%$ one (Figures 1Ec, 1Ed).

Table 3. Number of correct choices versus wrong ones - and proportion of correct responses - given by Myrmica ruginodis workers which received different diets

\begin{tabular}{|c|c|c|c|c|c|c|c|}
\hline \multirow{2}{*}{\multicolumn{2}{|c|}{$\begin{array}{c}\text { Experiments } \\
\text { Times } \\
\text { CS on the water }\end{array}$}} & \multicolumn{6}{|c|}{ Diet of tested ants and numerical results } \\
\hline & & \multicolumn{2}{|c|}{$0 \%$ of sugar } & \multicolumn{2}{|c|}{$20 \%$ of sugar } & \multicolumn{2}{|c|}{$60 \%$ of sugar } \\
\hline \multicolumn{2}{|c|}{ Control } & & \multicolumn{2}{|c|}{ with a green cube } & 9 vs 11 & $45 \%$ & \\
\hline \multirow[t]{4}{*}{ Tests } & $8 \mathrm{hrs}$ & 11 vs 9 & $55 \%$ & 14 vs 7 & $70 \%$ & 15 vs 5 & $75 \%$ \\
\hline & $21 \mathrm{hrs}$ & 10 vs 10 & $50 \%$ & 17 vs 3 & $85 \%$ & $16 v s 4$ & $80 \%$ \\
\hline & $32 \mathrm{hrs}$ & $9 v s 11$ & $45 \%$ & $18 v s 2$ & $90 \%$ & 16 vs 5 & $80 \%$ \\
\hline & $48 \mathrm{hrs}$ & $11 v s 9$ & $55 \%$ & $17 v s 3$ & $85 \%$ & $16 v s 4$ & $80 \%$ \\
\hline \multicolumn{2}{|c|}{ CS on the meat } & \multicolumn{2}{|c|}{$20 \%$ of sugar } & \multicolumn{2}{|c|}{$60 \%$ of sugar } & \multicolumn{2}{|c|}{$0 \%$ of sugar } \\
\hline \multicolumn{2}{|c|}{ Control } & \multicolumn{3}{|c|}{ with a yellow cub } & $11 v s 9$ & \multicolumn{2}{|l|}{$55 \%$} \\
\hline \multirow[t]{4}{*}{ Tests } & $8 \mathrm{hrs}$ & $16 v s 4$ & $80 \%$ & $15 v s 5$ & $75 \%$ & $9 v s 11$ & $45 \%$ \\
\hline & $20 \mathrm{hrs}$ & 17 vs 3 & $85 \%$ & $16 v s 4$ & $80 \%$ & $10 v s 10$ & $50 \%$ \\
\hline & $31 \mathrm{hrs}$ & 17 vs 3 & $85 \%$ & $16 v s 4$ & $80 \%$ & 10 vs 10 & $50 \%$ \\
\hline & $47 \mathrm{hrs}$ & $17 v s 3$ & $85 \%$ & $16 v s 4$ & $80 \%$ & $10 v s 10$ & $50 \%$ \\
\hline
\end{tabular}

E.g. either only tap water, or an aqueous solution of saccharose $20 \%$ or such a solution $60 \%$, the element to which the ants should be conditioned (= CS) being set either above the water solution or above the meat continuously provided. A black circle $(\bigcirc)$ ) indicates the acquisition of full conditioning and consequently the end of the training and the experiment. 


\section{Discussion}

The visual conditioning score and memory results obtained here are in agreement with those found during a detailed study of collective operant conditioning in the ant M. ruginodis (Cammaerts \& Nemeghaire, 2012). The present work shows that conditioning is largely impacted by the age, the activity and the diet of the animals.

\subsection{Age}

Very young ants could not acquire conditioning. This situation exists while such ants stay inside the nest. However, during this time period, the size of the callow ants' mushroom bodies (a part of the ants' brain) increases (Gronenberg, Heeren, \& Hölldobler, 1996). So, during their first weeks of life, young ants may acquire knowledge thanks to mechanisms others than conditioning, such as imprinting and/or habituation. Indeed, it has been shown that they then become imprinted to the odor of their nest entrances (Cammaerts, 2013b) and, a little later, to the specific odor of their foraging area (Cammaerts, submitted). It could be suggested that, for young ants, odors are perhaps more important than visual elements. Even though M. ruginodis middle-aged workers exclusively use their vision (Cammaerts et al., 2012a), very young ants are more sensitive to their congeners' odor than to these conspecific ants' visual aspect (Cammaerts \& Gosset, submitted). Such an acquisition of knowledge thanks to imprinting and/or habituation, as well as such importance of the odors during the early time of life, may be the case for other animal species, even if later on, learning and visual elements become more important (wasps: Signoretti, Guscelli, Simonelli, d'Ettorre, \& Cervo, 2013; human beings: Ward Platt, 2009). Conditioning acquisition ability is maximal when ants are middle-aged. This result is in agreement with the fact that ants of this age then learn their species' trail following behavior (Cammaerts, 2013c) and their specific alarm reaction (Cammaert, in press). Old workers retain nothing of their poor, difficult conditioning. So, an obvious age-polyethism also exists for conditioning abilities as it exists for many social tasks (Hölldobler \& Wilson, 1990). In nature, Myrmica spp workers live for about three years, the young, middle-aged and old ones being about 1,2 and 3 years old respectively, and a pronounced age-polyethism becomes automatically established in each colony.

This impact of age on animals' acquisition of long lasting knowledge is understood to occur in many species by ethologists and non-specialists, such as trainers or drillers of dogs or horses (Villers, 2013) and also by psychologists (Prull, Babrieli, \& Bunge, 2000).

\subsection{Foraging Activity}

When the ants had to find their food far from their nest, and were relatively more active in collecting food, they could not acquire efficient conditioning. The ants, which found their food quickly and easily, acquired efficient conditioning. This explains some common observations: for instance, during nest relocation, when ants have to rebuild some part of their nest, when sexuals are erratically moving in the foraging area, ready to fly away, it is practically impossible to obtain workers' conditioning. The ants are preoccupied by transporting larvae, by building or by protecting the alates respectively; they hardly forage and poorly acquire conditioning. This impact of activity, work or state of mind, on an animal's ability to acquire conditioning or knowledge is well known by drillers and trainers of several animal species. These persons select appropriate individuals and/or time periods for training or teaching (Villers, 2013). It is also known that animals must be not perturbed by unusual environment for acquiring efficient conditioning (Pavlov, 1927).

It must be precised that the colored hollow cube was a conditioned stimulus and not a visual cue which allowed ants navigating. To navigate, ants used cues located inside as well as outside of their tray, cues which were rather similar for the three experimented colonies and were constant in the course of the experiment.

From our results regarding the impact of ants' foraging activity on their conditioning (in fact their association between a perceived cue and the presence of food), it can be deduced that the elements located near the nest will be more easily memorized than those located far from the nest. This is logical since ants will encounter more often the cues located near the nest than those farther located. The ants will thus collect firstly any food found very near the nest, and only later that discovered far from the nest. Also, since cues located at greater distances are less memorized than the proximate ones and may change in the course of one trip, ants use chemical trails to help them returning to their nest after having collected food far from the nest or after having gone to cemeteries (Cammaerts, Morel, Martino, \& Warzée, 2012b). Such a deduction is valuable in the case of bees. For food sources located very near the nest, a simple eight dance is enough to help bees finding food and nest; when the food source is located far from the hive, a very informative waggle dance is necessary. In the latter case, bees use information about direction , distance and quality of food in order to situate the food and inform congeners about that location (von Frisch, 1946). 


\subsection{Consumption of Sugar}

The ants having received no sugary food could not be conditioned. Moreover, in this situation, four to ten very young ants died in three days. Sugary food appeared so to be essential, vital. This explains the natural diet of ants: they commonly eat aphids' honeydew, a highly sugared food (Leroy, Capella, \& Haubruge, 2009); Myrmica spp workers were often seen on flowers, near the nectarines (personal observation). We presume that ants eating primarily seeds or meat (Passera \& Aron, 2005) also look for some food containing carbohydrates and that leafcutter ants (same reference as above) find sugary elements in their common food.

On the other hand, several studies have shown the importance of glucose for efficient brain function (Lieberman, 2003). Each nerve cell, in fact, uses essentially glucose in order to function. The direct impact of sugar consumption on memory has also been demonstrated (Calvaresi \& Bryan, 2001). Our punctual results on ants' conditioning under different sugary food consumption conditions, find in the here above cited works, an obvious explanation.

\section{Acknowledgements}

We are very grateful to Mr. T. Sullivan who meticulously corrected the English of our paper and to an anonymous referee whose comments allowed us improving our paper.

\section{References}

Alaux, C., Ducloz, F., Crauser, D., \& Le Conte, Y. (2010). Diet effects on honeybee immunocompetence. Biology Letter, 6, 562-565. http://dx.doi.org/10.1098/rsbl.2009.0986

Calvaresi, E., \& Bryan, J. (2001). Vitamins, cognition and aging: a review. Journal of Gerontology, 327-339. http://dx.doi.org/10.1093/geronb/56.6.P327

Cammaert, M.-C., \& Gosset, G. Ontogenesis of visual and olfactory kin recognition in the ant Myrmmica sabuleti (Hymenoptera, Formicidae). Annales de la Société Entomologique de France, submitted.

Cammaerts M.-C., \& Nemeghaire, S. (2012). Why do workers of Myrmica ruginodis (Hymenoptera, Formicidae) navigate by relying mainly on their vision? Bulletin de la Société Royale Belge d'Entomologie, 148, 199-208.

Cammaerts, M.-C. (1977). Etude démograpique annuelle des sociétés de Myrmica rubra L. des environs de Bruxelles. Insectes Sociaux, 24, 147-161. http://dx.doi.org/10.1007/BF02227168

Cammaerts, M.-C. (2004a). Classical conditioning, temporal learning and spatial learning in the ant Myrmica sabuleti. Biologia, 59, 243-256.

Cammaerts, M.-C. (2004b). Operant conditioning in the ant Myrmica sabuleti. Behavioral Processes, 67, 417-425. http://dx.doi.org/10.1016/j.beproc.2004.07.002

Cammaerts, M.-C. (2007). Colour vision in the ant Myrmica sabuleti MEINERT, 1861 (Hymenoptera: Formicidae). Myrmecological News, 10, 41-50.

Cammaerts, M.-C. (2013a). Age dependent spatio-temporal learning in the ant Myrmica sabuleti (Hymenoptera, Formicidae). Bulletin de la Société Royale Belge d'Entomologie, 149, in press.

Cammaerts, M.-C. (2013b). Ants' learning of nest entrance characteristics (Hymenoptera, Formicidae). Journal of Entomological Research, 6.

Cammaerts, M.-C. (2013c). Learning of trail following behaviour by young Myrmica rubra workers (Hymenoptera, Formicidae). ISRN Entomology, 6.

Cammaerts, M.-C. Learning of foraging area specific odor by ants (Hymenoptera, Formicidae). Research Trends, submitted.

Cammaerts, M.-C. Learning of the specific alarm pheromone by young workers of the ant Myrmica sabuleti. Journal of Insect Sciences, in press.

Cammaerts, M.-C., \& Cammaerts, D. (2009). Light thresholds for colour vision in the workers of the ant Myrmica sabuleti (Hymenoptera: Formicidae). Belgian Journal of Zoology, 138, 40-49.

Cammaerts, M.-C., Morel, F., Martino, F., \& Warzée, N. (2012b). An easy and cheap software-based method to assess two-dimensional trajectories parameters. Belgian Journal of Zoology, 142, 145-151. 
Cammaerts, M.-C., Rachidi, Z., \& Cammaerts, D. (2011). Collective operant conditioning and circadian rhythms in the ant Myrmica sabuleti (Hymenoptera, Formicidae). Bulletin de la Société Royale Belge d'Entomologie, $147,142-154$.

Cammaerts, M.-C., Rachidi, Z., Beke, S., \& Essaadi, Y. (2012a). Use of olfactory and visual cues for traveling by the ant Myrmica ruginodis (Hymenoptera, Formicidae). Myrmecological News, 16, 45-55.

Cammaerts, M.-C., \& Cammaerts, R. (1980). Food recruitment strategies of the ants Myrmica sabuleti and Myrmica ruginodis. Behavioural Processes, 5, 251-270. http://dx.doi.org/10.1016/0376-6357(80)90006-6

Cheng, K., \& Wehner, R. (2002). Navigating desert ants (Cataglyphis fortis) learn to alter their search patterns on their homebound journey. Physiological Entomology, 27, 285-290. http://dx.doi.org/10.1046/j.1365-3032.2002.00298.x

Chittka, L., \& Muller, H. (2009). Learning, specialization, efficiency and task allocation in social insects. Communicative \& Integrative Biology, 2, 151-154.

Chittka, L., \& Peng, F. (2013). Caffeine boots bees' memories. Science, 339, 8. http://dx.doi.org/10.1126/science.1234411

Dornhaus, A., \& Franks, N. R. (2008). Individual and collective cognition in ants and other insects (Hymenoptera: Formicidae). Myrmecological News, 11, 215-226.

Dupuy, F., Sandoz, J. C., Giurfa, M., \& Josens, R. (2006). Individual olfactory learning in Camponotus ants. Animal Behavior, 72, 1081-1091. http://dx.doi.org/10.1016/j.anbehav.2006.03.011

Giurfa, M. (2003). The amazing mini-brain: lessons from a honey bee. Bee World, 84, 5-18.

Gronenberg, W., Heeren, S., \& Hölldobler, B. (1996). Age-dependent and task-related morphological changes in the brain and the mushroom bodies of the ant Camponotus floridanus. Journal of Experimental Biology, 199, 2011-2019.

Guerrieri, F., \& d'Ettorre, P. (2010). Associative learning in ants: conditioning of the maxilla-labium extension response in Camponotus aethiops. Journal of Insect Physiology, 56, 88-92. http://dx.doi.org/10.1016/j.jinsphys.2009.09.007

Hölldobler, B., \& Wilson, E. O. (1990). The ants (p. 732). Harvard University Press, Springer-Verlag Berlin.

Laloi, D., Sandoz, J. C., Picard-Nizou, A. L., Marchesi, A., Pouvreau, A., Tasei, J. N., ... Pham-Delègue, M. H. (1999). Olfactory conditioning of the proboscis extention in bumble bees. Entomologia Experimentalis et Applicata, 90, 123-129. http://dx.doi.org/10.1046/j.1570-7458.1999.00430.x

Leroy, P., Capella, Q., \& Haubruge, E. (2009). L'impact du miellat de puceron au niveau des relations tritrophiques entre les plantes-hôtes, les insectes ravageurs et leurs ennemis naturels. Biotechnology, Agronomy, Society and Environment, 13, 325-334. Retrieved from http://popups.ulg.ac.be/Base/document.php?id=4171.

Lieberman, H. R. (2003). Nutrition, brain function and cognitive performance. Appetite, 245-254. http://dx.doi.org/10.1016/S0195-6663(03)00010-2

Matsumoto, Y., Menzel, R., Sandoz, J. C., \& Giurfa, M. (2012). Revisiting olfactory classical conditioning of the proboscis extension response in honey bees: a step toward standardized procedures. Journal of Neuroscience Methods, 211, 159-167. http://dx.doi.org/10.1016/j.jneumeth.2012.08.018

Passera, L., \& Aron, S. (2005). Les fourmis: comportement, organisation sociale et évolution (p. 480). Ottawa, Canada: Les Presses Scientifiques du CNRC.

Pavlov, I. P. (1927). Conditioned reflexes. An investigation of the physiological activity of the cerebral cortex (p. 142). Translated and edited by G. V. Anrep. London: Oxford University Press.

Pearce, J. M. (1997). Animal Learning and Cognition: an introduction (p. 333). Hove: Psychology Press.

Prull, M. W., Babrieli, J. D. E., \& Bunge, S. A. (2000). Ch. 2. Age-related changes in memory: A cognitive neuroscience perspective. In Craik FIM, Salthouse TA. The handbook of aging and cognition. Erlbaum. ISBN 978-0-8058-2966-2.

Rachidi, Z., Cammaerts, M.-C., \& Debeir, O. (2008). Morphometric study of the eye of three species of Myrmica (Formicidae). Belgian Journal of Entomology, 10, 81-91.

Schwarz, S., \& Cheng, K. (2010). Visual associative learning in two desert ant species. Behavioral Ecology and 
Sociobiology, 64, 2033-2041. http://dx.doi.org/10.1007/s00265-010-1016-y

Siegel, S., \& Castellan, N. J. (1989). Nonparametric statistics for the behavioural sciences (p. 396). Singapore: McGraw-Hill Book Company.

Signorotti, L., Guscelli, E, Simonelli, P., d'Ettorre, P., \& Cervo, R. (2013). Preimaginal learning and nestmate recognition in the paper wasp Polistes dominula. Colloque de la section française de l'IUSSI, Villetaneuse.

Skinner, B. J. (1938). The behavior of organisms: an experimental analysis (p. 457). New York: Appleton-Century-Crofts.

Skinner, B. J. (1966). Operant Behavior. In W. K. Honig (Ed.) (pp. 1-27). New York: Appleton-Century-Crofts.

Villers, E. (2013). Le chien, le cheval et une seule méthode. Hebdos du Suroît, première édition. Vaudreuil-Dorion.

Von Frisch, K. (1946). Die Tänze der Bienen. Österreichische Zoologische Zeitschrift, 1, 1-48.

Ward Platt, M. (2009). Le guide essentiel pour le développement de votre enfant, de 0 à 5 ans. In B. Wurman \& R. Saul (Eds.) (p. 240).

Watson, J. B. (1925). Behaviorism (pp. 180-190). New York, NY: W. W. Norton \& Company, Inc.

Watson, J. B. (1932). Behaviorism. American Journal of Psychiatry, 89, 187-189.

\section{Copyrights}

Copyright for this article is retained by the author(s), with first publication rights granted to the journal.

This is an open-access article distributed under the terms and conditions of the Creative Commons Attribution license (http://creativecommons.org/licenses/by/3.0/). 